\title{
La liane mystérieuse des Wayana, film de Luc RIOLON, IRD audiovisuel, Paris, 26 minutes
}

Philippe Erikson

\section{OpenEdition \\ Journals}

Édition électronique

URL : https://journals.openedition.org/jsa/2926

DOI : 10.4000/jsa.2926

ISSN : 1957-7842

Éditeur

Société des américanistes

\section{Édition imprimée}

Date de publication : 5 janvier 2005

Pagination : 251-253

ISSN : 0037-9174

\section{Référence électronique}

Philippe Erikson, "La liane mystérieuse des Wayana, film de LuC RIolon, IRD audiovisuel, Paris, 26 minutes », Journal de la Société des américanistes [En ligne], 91-1 | 2005, mis en ligne le 29 septembre 2006, consulté le 03 septembre 2022. URL : http://journals.openedition.org/jsa/2926 ; DOl : https://doi.org/10.4000/jsa.2926

Ce document a été généré automatiquement le 3 septembre 2022.

Tous droits réservés 


\title{
La liane mystérieuse des Wayana, film de Luc RIOLON, IRD audiovisuel, Paris, 26 minutes
}

\author{
Philippe Erikson
}

1 Présenté du 10 février 2004 au 6 mars 2005 dans le cadre de l'exposition Piranhas enivrés au Musée de l'aquarium tropical de la Portée Dorée, ce DVD a le mérite d'éclairer quelques facettes du métier d'ichtyologue, tout en apportant d'appréciables informations écoethnologiques sur la pêche «à la nivrée » et, dans une moindre mesure, sur la vie des Wayana.

2 Le film relate le déroulement d'une mission scientifique en Guyane française. Sous la direction du narrateur, l'ichtyologue Michel Jégu, on voit évoluer une équipe comprenant des chercheurs de l'INRA, du CNRS, de l'IRD ainsi que des Muséums d'histoire naturelle de Paris et de Genève, tous venus étudier l'impact de la « nivrée » sur la communauté aquatique (les invertébrés autant que les poissons). "Appâté » par le sujet, le spectateur sera peut-être un peu frustré par le manque d'informations sur les résultats de l'enquête. On apprend seulement, assez incidemment, que les petits poissons délaissés par les pêcheurs - mais récupérés, pesés et mis dans le formol par les chercheurs - forment un ensemble comprenant des individus d'espèces de petite taille plutôt que des juvéniles de celles qui intéressent les Amérindiens !

3 Les informations techniques sur la pêche elle-même, sans apporter rien de nouveau, sont néanmoins abondantes et précises. Le spectateur entendra, tout en contemplant de belles images du fleuve Maroni, l'essentiel de ce qu'il faut savoir sur cette : « liane au pouvoir étonnant [que] les Wayana appellent ali ali [...] ; liane rare, [qui] pousse très lentement ». Les citations suivantes, extraites du commentaire, illustrent cette dimension didactique du film :

Le terme de «nivrée " trouve son origine au XVII ${ }^{\mathrm{e}}$ siècle. Les voyageurs de l'époque disaient que les poissons étaient comme saouls, enivrés, [...] les nivrées ont lieu à l'étiage, au moment où le niveau du fleuve est le plus bas. [...] lavées dans le courant, les lianes ali ali libèrent une substance laiteuse extrêmement puissante appelée roténone [...]. La roténone agit sur la respiration des poissons en bloquant 
le transfert de l'oxygène de l'eau vers le sang au travers des branchies [...]. En quelques secondes, les poissons sont asphyxiés. Ils remontent à la surface avant de mourir, de couler ou d'être emportés par le courant [...]. La molécule active ne pénètre pas dans les muscles des poissons qui peuvent donc être consommés sans danger [...]. Toutes les espèces de poissons sont sensibles à la roténone. Heureusement, cette molécule en suspension dans l'eau est très peu stable et rapidement inactivée par la lumière et la chaleur.

Si le film est donc suffisamment instructif pour ce qui relève purement de l'halieutique, on peut en revanche regretter de ne rien apprendre sur la symbolique inhérente à cette pêche au poison et, somme toute, assez peu sur le point de vue amérindien. Tout au plus nous donne-t-on à voir des dessins de poissons, inspirés par la mythologie, recueillis à l'école d'Antecume Pata par l'ethnologue de l'équipe, Hélène Pagezy. À l'évidence, les relations entre les Wayana et les chercheurs ont été, tout au long du tournage, relativement tièdes. Non sans honnêteté, le réalisateur-monteur l'a par exemple montré dans cette scène où l'on entend un Wayana (sous-titré) s'interroger sur ce que font vraiment les Blancs ou, dans telle autre scène, où l'on voit les pêcheurs se régaler de poissons et de cassaves fraîches, tandis que les scientifiques se font réchauffer d'assez peu réjouissantes boîtes de conserve. Le commentaire nous apprend qu'à l'exception de Yann Nanuk et de ses proches, personne ne voulait vraiment se laisser filmer, d'où sans doute le faible nombre de participants et le caractère bien peu festif de l'expédition qui nous est donnée à voir. Du coup, le film perd un peu de sa capacité à illustrer, ne serait-ce que par l'image, l'enchâssement récurrent, dans cette partie du monde, des thèmes de la pêche au poison et de l'ambivalence de toute fête de conjonction : entre les sexes, entre vivants et habitants l'infra-monde aquatique, entre alliés politiques réunis autour d'une bière de manioc aussi blanche que la nivrée...

On peut également déplorer que ce film occulte totalement la lancinante question que pose cet autre poison, autrement plus néfaste que la roténone, qu'est le mercure massivement déversé par les orpailleurs clandestins en Guyane française, au détriment des ressources halieutiques des Wayana (entre autres). La FOAG (Fédération des organisations amérindiennes de Guyane) a déposé le 15 janvier 2001 une plainte contre $\mathrm{X}$ (toujours en cours d'instruction) pour empoisonnement et l'on s'attend malheureusement à ce que des troubles neurologiques irréversibles frappent massivement les prochaines générations de Wayana (Charlet et Boudou 2002). Tant la courtoisie envers ses hôtes que la thématique du film auraient dû inciter le réalisateur à en glisser au moins un mot dans le commentaire.

Inutile cependant de se montrer excessivement sévère. En dépit de son titre aguicheur et de sa bande-son qui démarre joliment avec de la flûte en os wayana pour finir ethnocentriquement avec de la " world music » (musique originale de Félix Sabal Lecco), La liane mystérieuse des Wayana est un véritable film de chercheur, susceptible de fournir un excellent support didactique pour un cours d'introduction à l'ethno-écologie ou à l'ethnographie des sociétés amazoniennes. On imagine très bien le parti que les enseignants pourraient en tirer, en l'associant à des lectures plus denses sur la taxinomie, la biogéographie et l'ethnobotanique des plantes ichtyotoxiques (Moretti et Grenand 1982), ainsi que sur leur rôle dans l'univers symbolique (Descola 1986, chap. VII) et la mythologie (Bolens-Duvernay 1983) des Amazoniens. Sans oublier, bien sûr, de recommander quelques lectures sur les ravages du mercure en Guyane française. 


\section{BIBLIOGRAPHIE}

CHARLET Laurent et Alain BOUDOU

2002 « L'or et le poison ", La Recherche, 359, pp. 52-59.

DESCOLA Philippe

1986 La Nature domestique, Éditions de l'EHESS, Paris.

BOLENS-DUVERNAY Jacqueline

1983 « Avatars mythiques du poison de pêche », L'Homme, 23 (1), pp. 45-59.

MORETTI Christian et Pierre GRENAND

1982 « Les nivrées ou plantes ichtyotoxiques de la Guyane française », Journal of

Ethnopharmacology, 6, pp. 139-160.

\section{AUTEURS}

\section{PHILIPPE ERIKSON}

Université Paris X-Nanterre 